\title{
SPRAY FORMED SUPERALLOY 625 PIPING
}

\author{
A L. Moran* and R.E. Rebis+ \\ *Department of Mechanical Engineering, United States Naval $\Lambda$ cademy \\ +Survivability, Structures, and Materials Directorate, \\ Carderock Division, Naval Surface Warfare Center \\ Annapolis MD 21402, USA
}

\begin{abstract}
Spray formed Alloy 625 piping subjected to standard amounts of cold reduction performed comparably to conventionally processed Alloy 625 piping and met the chemical analysis specifications and metallurgical requirements for porosity, oxide content and grain size required for Navy applications. Mechanical testing indicated that the tensile strength and ductility of roll extruded and pilger rolled pipes easily exceeded the minimum requirements while results of the hardness testing and Charpy impact testing showed no significant difference between as-sprayed preforms, spray formed and processed thin-walled piping, and conventionally produced piping. Results of fatigue testing of spray formed Alloy 625 pipes indicated that post processing is necessary to achieve the fatigue performance in terms of endurance limit of conventionally processed Alloy 625 pipes. Of the two post processing methods employed in this study, both methods diminished porosity and produced a fine grain size but roll-extrusion yielded a more uniform microstructure and better fatigue and strength properties. A weldability evaluation indicated that the hot-cracking resistance and mechanical properties of welded, spray formed Alloy 625 products were at least equivalent to that of conventional Alloy 625. Additionally, spray formed Alloy 625 piping performed comparably in service testing to wrought piping. Thus, Alloy 625 piping produced from spray formed tubulars appears to be a viable substitute for conventionally produced Alloy 625 piping.
\end{abstract}

\section{Introduction}

The Metals Department of the Carderock Division of the Naval Surface Warfare Center conducted an evaluation of spray formed Alloy 625 piping under the sponsorship of the Office of the Secretary of Defense Foreign Comparative Test Program. Spray forming, developed by Osprey Metals, Ltd in the United Kingdom, produces a characteristic fine equiaxed microstructure in a near net shape product [1]. The objective of the evaluation was to characterize the as-deposited spray formed Alloy 625 preforms and determine if these preforms could be processed into piping meeting current specification requirements and exhibiting equivalent or improved properties in comparison to conventionally produced piping. Three sizes of NPS (Nominal Pipe Size) Class 850 Alloy 625 pipe $(10.2,20.3$ and $35.6 \mathrm{~cm}$ ), produced to Electric Boat specification $3200 \mathrm{C}$ on Pipe and Tube, Seamless, Nickel-Chromium-Molybdenum Alloy Procurement, date 1989, were tested as

\footnotetext{
Superalloys 718,625,706 and Various Derivatives Edited by E.A. Loria

The Minerals, Metals \& Materials Society, 1997
} 
representative of the range of sizes producible by the spray forming technique. In order to obtain material for testing, a contract was awarded to Sandvik Steel in Sandviken, Sweden to produce Alloy 625 as-sprayed preforms and finished piping via the Osprey spray forming process. [2] Four as-sprayed tubular preform scctions were provided for evaluation. Additional as-sprayed preforms were cold worked and reduced to the final EB 3200C specification dimensions by either pilger rolling at Sandvik or roll extrusion at Kaiser Rollmet in Irvine, California. Since the pilger rolling process is typically limited to tubulars less than $25.4 \mathrm{~cm}$ in diameter, roll extrusion was required on the larger diameter piping.

\section{Experimental Results}

NSWC-CD conducted testing to verify the chemical, dimensional, metallurgical and mechanical properties of the Alloy 625 spray formed material.

\section{Chemical and Microstructural Analysis}

Chemical analyses of the spray formed preforms and finished thin-walled piping were performed in accordance with ASTM E38, E354 and Fed-STD-151 method 112.. All of the Alloy 625 spray formed preforms and piping met the chemical analysis specifications required in Electric Boat 3200C. Differences between piping derived from spray formed tubulars and conventional ingot castings appeared to be the level of carbon and nitrogen in each alloy. The spray formed product was generally lower in carbon and higher in nitrogen. Both the carbon and the nitrogen contribute to the formation of carbonitrides in the alloy. For the preforms, the average porosity was less than $0.04 \%$, well below the accepted $2 \%$ porosity level, with the pores being very fine in size, evenly shaped and discontinuous. The range of average grain size was between 30 to 45 microns, well below the required average grain size of less than 100 microns. The $10.2 \mathrm{~cm}$ spray formed/pilger rolled piping had an average grain size of 14 microns and several carbide bands, which are formed during the pilger rolling process. Although the grain sizes of the roll extruded and pilger rolled materials were similar, the spray formed/roll extruded microstructure appeared to be more uniform than the spray formed/pilger rolled microstructure. The average grain size for the pilger rolled as well as the roll extruded piping was between to 10-15 microns. The porosities for all the finished piping were less than $0.03 \%$ for the roll extruded and $0.02 \%$ for the pilger rolled materials.

\section{Non-destructive Evaluation}

Penetrant testing (PT) of the $10.2 \mathrm{~cm}$ pilger rolled piping was conducted in accordance with MILSTD-271 on a $24.5 \mathrm{~m}$ length of piping from twenty pipe sections. The inspected area was $100 \%$. In accordance with NAVSEA 9000-LP-003-8000, any discontinuity exceeding $0.16 \mathrm{~cm}$ was considered a rejectable indication. Nine indications were detected that exceeded the criteria. Seven of nine indications were $0.41 \mathrm{~cm}$ in length or less. The results of the penetrant testing (100\%) of both 20.3 $\mathrm{cm}$ roll extruded and $20.3 \mathrm{~cm}$ pilger rolled piping noted 67 indications detected over $4.4 \mathrm{~m}$ of pipe, while the pilger rolled material had 21 indications detected over $10.2 \mathrm{~m}$ of pipe. For the $35.6 \mathrm{~cm}$ piping, the inspected area ranged from 90 to $100 \%$. A total of 10 indications were found over the $24 \mathrm{~m}$ of $35.6 \mathrm{~cm}$ piping inspected and 9 out of the 10 indications were less than $0.64 \mathrm{~cm}$ long. Surface indications that exceed the rejectable criteria can be ground out if the following requirements are satisfied.

The results of the ultrasonic testing (UT), completed according to MLL-STD-271F, of the $10.2 \mathrm{~cm}$ pilger rolled, $20.3 \mathrm{~cm}$ pilger rolled, $20.3 \mathrm{~cm}$ rolled extruded piping indicated that no rejectable 
indications were detected. In addition, no rejectable indications were detected on the as-sprayed and machined preforms. Ultrasonic testing of the $35.6 \mathrm{~cm}$ piping was performed on approximately $80 \%$ of the pipe area. Rejectable indications were detected in three pipes. All of the rejectable indications exceeded $100 \%$ full screen height (FSH). One pipe had two rejectable indications, one measuring $0.28 \mathrm{~cm}$ deep, the other $0.53 \mathrm{~cm}$ deep. The second pipe also had two rejectable indications, one measuring $0.46 \mathrm{~cm}$ deep, the other $0.30 \mathrm{~cm}$ deep. The third pipe had one rejectable indication measuring $0.36 \mathrm{~cm}$ deep.

\section{Mechanical Testing}

The tensile properties for the finished thin-walled piping and as-sprayed preforms are listed in Table I. The yield stresses of the roll extruded and pilger rolled pipes exceeded the $379 \mathrm{MPa}$ minimum requirement. The roll extruded pipes $(20.3 \mathrm{~cm}$ and $35.6 \mathrm{~cm})$ and the conventional pipe well exceeded the minimum yield stress, while the yield stresses of the pilger-rolled pipes were lower. The difference is attributed to different reduction/annealing cycles used by the different manufacturers. The pilger-rolled, roll extruded and conventionally processed pipes all exhibited similar ultimate stresses ranging from 940 to $968 \mathrm{MPa}$, which exceeded the $758 \mathrm{MPa}$ minimum requirement. The $20.3 \mathrm{~cm}$ pilger-rolled pipe showed a slightly lower ultimate stress of $896 \mathrm{MPa}$. The percent elongation for all the pipes met the minimum $30 \%$, ranging from 38 to $41 \%$. These values were 10 to $20 \%$ lower than the preforms. This reduction was expected due to the strain-hardening induced during the pipe finishing process. The yield stress of the as-sprayed preforms were all below the specified minimum value for reduced piping, while the ultimate stress exceeded the minimum requirement. The elongation values of the preforms also exceeded the minimum value of $30 \%$. The values ranged from 49 to $59 \%$. These lower strength, higher ductility as-sprayed preforms were intentionally produced to facilitate workability during pilger rolling and roll extruding.

Average Brinell hardness measurements for the as-sprayed preforms were between 183 and 197 for both outer and inner diameters. Corresponding Rockwell hardness measurements ranged from RHB 87 to RHB 94. The average hardness was $95 \mathrm{RHB}$ for the $10.2 \mathrm{~cm}$ pipe, RHB 96 for the $20.3 \mathrm{~cm}$ pilger-rolled pipe, and RHB 99 for the $35.6 \mathrm{~cm}$ pipe. Average hardness levels of the $20.3 \mathrm{~cm}$ roll-extruded pipe and conventional pipe were 23 and 24 RHC, respectively.

Results of the Charpy impact toughness tests are shown in Table II. Comparisons can only be made among specimens of equivalent size. The room temperature impact energies for the $0.32 \mathrm{~cm}$ subsize specimens ranged form 22 to $27 \mathrm{~J}$ for the preforms and from 14 to $23 \mathrm{~J}$ for the finished pipes. At these small energy levels it is difficult to assess whether the difference in energy is significant. The specimens that exhibited the lower energy levels came from two different preforms and were processed differently. Therefore, there does not appear to be a correlation to the source of the material. At $-73^{\circ} \mathrm{C}$ the energy levels for the $20.3 \mathrm{~cm}$ conventional and $35.6 \mathrm{~cm}$ roll-extruded pipes averaged $20 \mathrm{~J}$, and the $20.3 \mathrm{~cm}$ pilger-rolled and roll-extruded pipes averaged $11 \mathrm{~J}$.

The fatigue performance in air of as-deposited spray formed Alloy 625 preforms compared to that of conventionally processed Alloy 625 is shown in Figure 1. This testing was conducted to determine a baseline fatigue curve for the as-sprayed product prior to cold-working by the roll extrusion and pilgering processes. The data includes three different as-sprayed preforms that were subsequently processed into $10.2 \mathrm{~cm}, 20.3 \mathrm{~cm}$ and $35.6 \mathrm{~cm}$ nominal diameter pipes. As expected, the stress vs. number of cycles $(\mathrm{S}-\mathrm{N})$ curves indicate that the fatigue performance of the as-sprayed preforms is inferior to the fatigue performance of the specimens from conventionally processed pipe when tested in air. However, after post processing of the spray formed preforms by means of roll-extrusion, the fatigue performance in air is comparable to that of the conventionally processed material, as shown 
Table I. Strength properties for spray formed Alloy 625 preforms and piping.

\begin{tabular}{|c|c|c|c|}
\hline MATERIAL & $\begin{array}{c}\text { 0.2\% YIELD STRESS } \\
\text { (MPa)Ave. of two tests }\end{array}$ & $\begin{array}{c}\text { ULTIMATE TENSILE } \\
\text { STRENGTH (MPa) }\end{array}$ & $\begin{array}{c}\text { PERCENT } \\
\text { ELONGATION }\end{array}$ \\
\hline 10.2 CM PREFORM & 361 & 785 & 56 \\
\hline 20.3 CM PREFORM & 371 & 789 & 59 \\
\hline 20.3 CM PREFORM & 330 & 773 & 49 \\
\hline 35.6 CM PREFORM & 360 & 782 & 57 \\
\hline 10.2 CM PILGER PIPE & 459 & 954 & 42 \\
\hline 20.3 CM PILGER PIPE & 480 & 896 & 38 \\
\hline 20.3 CM ROLLED PIPE & 595 & 962 & 41 \\
\hline 20.3 CM ROLLED PIPE & 568 & 940 & 41 \\
\hline 20.3 CM CONV. MFG. & 561 & 968 & 41 \\
\hline 35.6 CM ROLLED PIPE & 561 & 953 & 30 \\
\hline EB3200C SPEC & 379 & 758 & 42 \\
\hline
\end{tabular}

Table II. Charpy V-notch impact toughness of spray formed preform and Alloy 625 pipe.

\begin{tabular}{|c|c|c|}
\hline MATERIAL & 3 TEST AVE. ENERGY AT RT (J) & AVE.ENERGY AT -73C (J) \\
\hline $\begin{array}{c}\text { FULL SIZE 1.00CM SAMPLES } \\
10.2 \text { CM PREFORM }\end{array}$ & 115 & - \\
\hline 20.3 CM PREFORM & 96 & - \\
\hline $\begin{array}{c}\text { SUBSIZE 0.76CM SAMPLES } \\
20.3 \text { CM PREFORM }\end{array}$ & 73 & - \\
\hline 35.6 CM PREFORM & 68 & - \\
\hline $\begin{array}{c}\text { SUBSIZE 0.32CM SAMPLES } \\
10.2 \text { CM PREFORM }\end{array}$ & 23 & - \\
\hline 20.3 CM PREFORM & 23 & - \\
\hline 20.3 CM PREFORM & 27 & - \\
\hline 35.6 CM PREFORM & 22 & - \\
\hline 20.3 CM PILGERED PIPE & 14 & 11 \\
\hline 20.3 CM EXTRUDED PIPE & 14 & 11 \\
\hline 20.3 CM EXTRUDED PIPE & 22 & - \\
\hline $20.3 \mathrm{CM}$ CONV MFG PIPE & 23 & 22 \\
\hline 35.6 CM EXTRUDED PIPE & 20 & 20 \\
\hline $\begin{array}{c}\text { SUBSIZE 0.27CM SAMPLES } \\
\text { 10.2 CM PILGERED PIPE }\end{array}$ & 19 & - \\
\hline 35.6 CM EXTRUDED PIPE & 16 & - \\
\hline
\end{tabular}




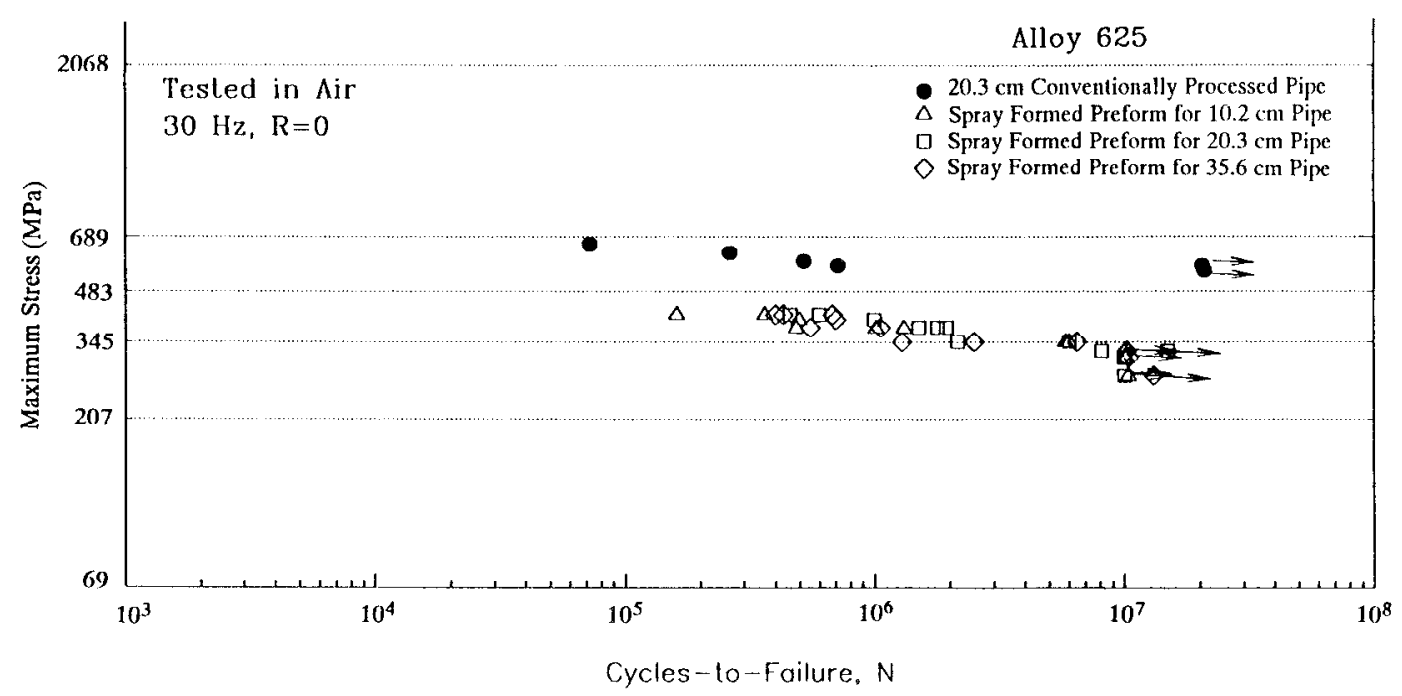

Figure 1. S-N curve for spray formed Alloy 625 pipe preforms tested in air.

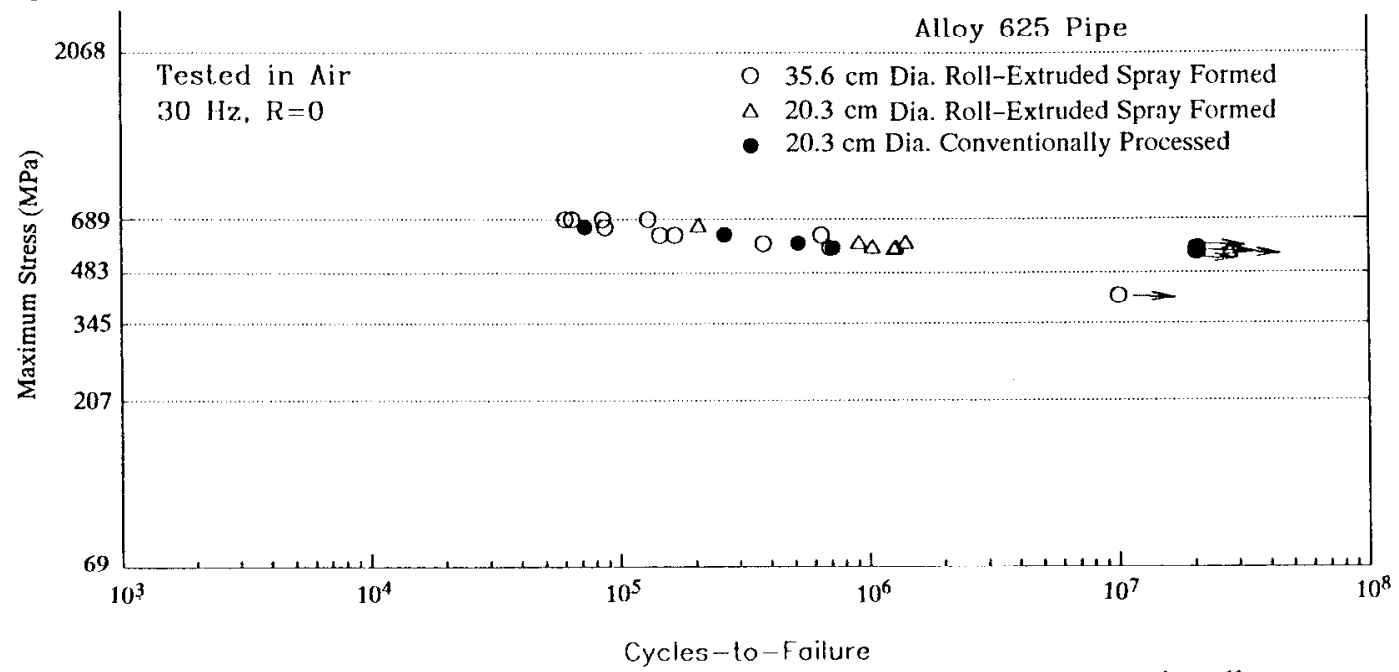

Figure 2. S-N curve for the spray formed Alloy 625 roll-extruded and conventionally processed

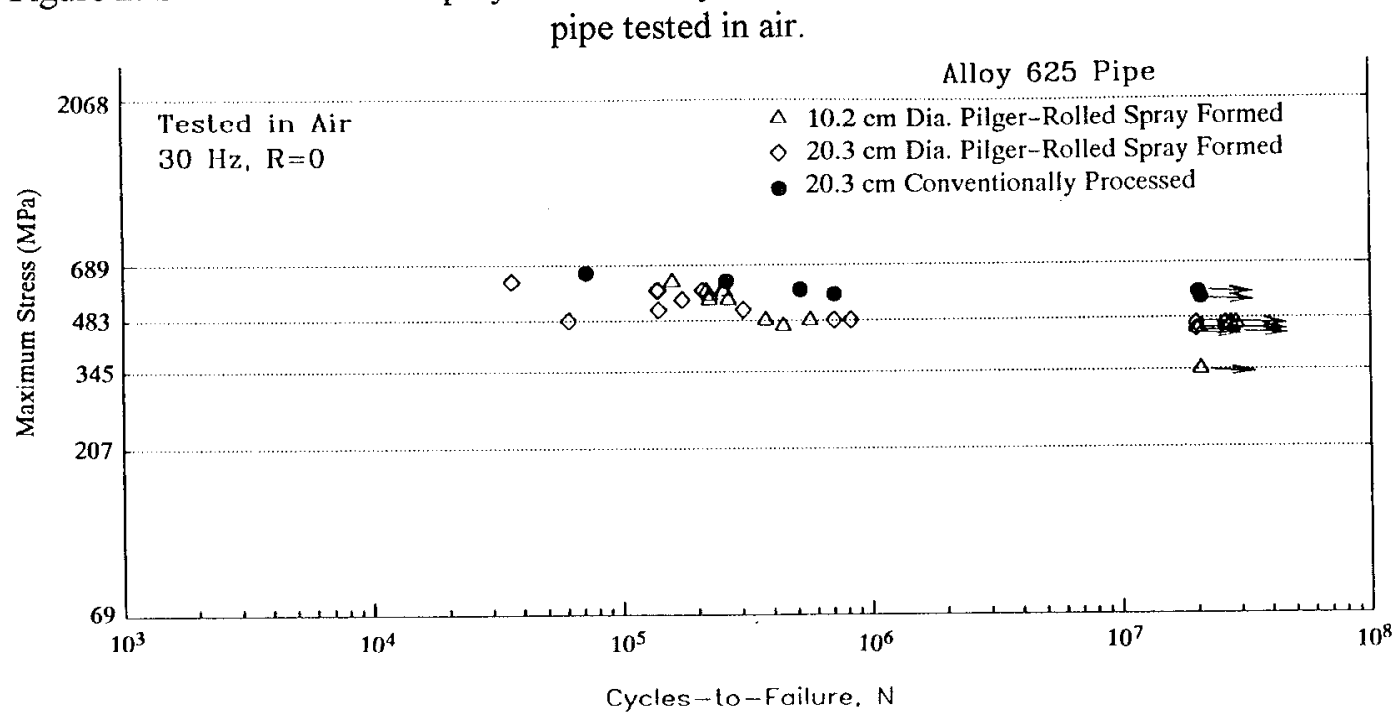

Figure 3. S-N curve for the spray formed Alloy 625 pilger-rolled and conventionally processed pipe tested in air. 
in Figure 2. Figure 3 shows that post processing of the spray formed preforms by means of pilger-rolling improves fatigue performance in air compared to that of the preforms, but not to the same level as the conventionally processed and spray formed roll-extruded material.

The fatigue performance of the roll-extruded spray formed and pilger-rolled spray formed Alloy 625 piping compared to that of the conventionally processed Alloy 625 piping when tested in $3.5 \% \mathrm{NaCl}$ seawater is shown in Figures 4 and 5, respectively. The fatigue data in seawater of both spray formed (and subsequently processed) materials seems to compare well with the data of the conventionally processed Alloy. The run out stresses for the spray formed materials were slightly below that of the conventionally processed Alloy, but may be considered to lie within the scatter of the data.

The results of fatigue tests in air and seawater were performed on specimens from weldments made in a roll extruded spray formed Alloy 625 pipe and conventionally processed Alloy 625 pipe using the GTAW process. These specimens were tested with the weld reinforcement intact. This resulted in a reduced fatigue performance due to this notch factor. The S-N curves indicated that the weldments in the spray formed roll-extruded pipe performed as well as weldments in conventionally processed pipe in both environments. The fatigue strengths of specimens from GTAW weldments of both the roll-extruded spray formed pipe and the conventionally processed pipe were slightly lower in the seawater environment compared to the data collected in air.

Fatigue data was also gathered from testing specimens from roll-extruded spray formed Alloy 625 pipe and conventionally processed Alloy 625 pipe, welded using the GTAW ront, SMAW fill procedure, in air and seawater environments. In each environment, the spray formed roll-extruded pipe weldment data was within the scatter of the conventionally processed pipe weldment data. The seawater environment seemed to have a slightly negative effect on both the roll-extruded spray formed and conventionally processed Alloy 625 weldments, but to an equal extent.

\section{Weldability Assessment}

A number of methods have been applied to estimate and compare hot cracking susceptibilities from hot ductility test data. Recently, Lippold et al. [3] developed a methodology that uses melting temperature, zero ductility temperature, zero strength temperature, and ductility recovery temperature to evaluate cracking susceptibility. Their method uses these four parameters to define a thermal crack susceptible region. The thermal crack susceptible region represents a heat affected zone region surrounding the weld pool within which the material has no ductility and is thus susceptible to hot cracking. The thermal crack susceptible region has an on-heating component and an on-cooling component. These components account for the possibility of initiating a heat affected zone hot crack during weld heating or cooling (i.e., at locations ahead of or bchind the instantancous weld center). The on-heating component of the thermal crack susceptible region, termed the on-heating crack susceptible region, is defined as the difference between molting tempcraturc and the zero ductility temperature. The higher the value for this value, the greater the susceptibility to hot cracking during the heating cycle. The on-cooling component of the crack susceptible rcgion, known as the brittle temperature range, is defined as the difference between the peak temperature used in the on-cooling phase and the ductility recovery temperature. The brittle temperature range is a function of peak temperature and represents the range that has no ductility during the cooling portion of the weld. Increasing brittle temperature range values indicate higher susceptibility to hot cracking. Table III presents the extent of the thermal crack susceptible region for the spray formed alloy 625 preforms as compared to data reported for conventional alloy 625 . The data show that the crack susceptible region of spray formed alloy 625 compares well to the conventional alloy 625 crack susceptible region. 


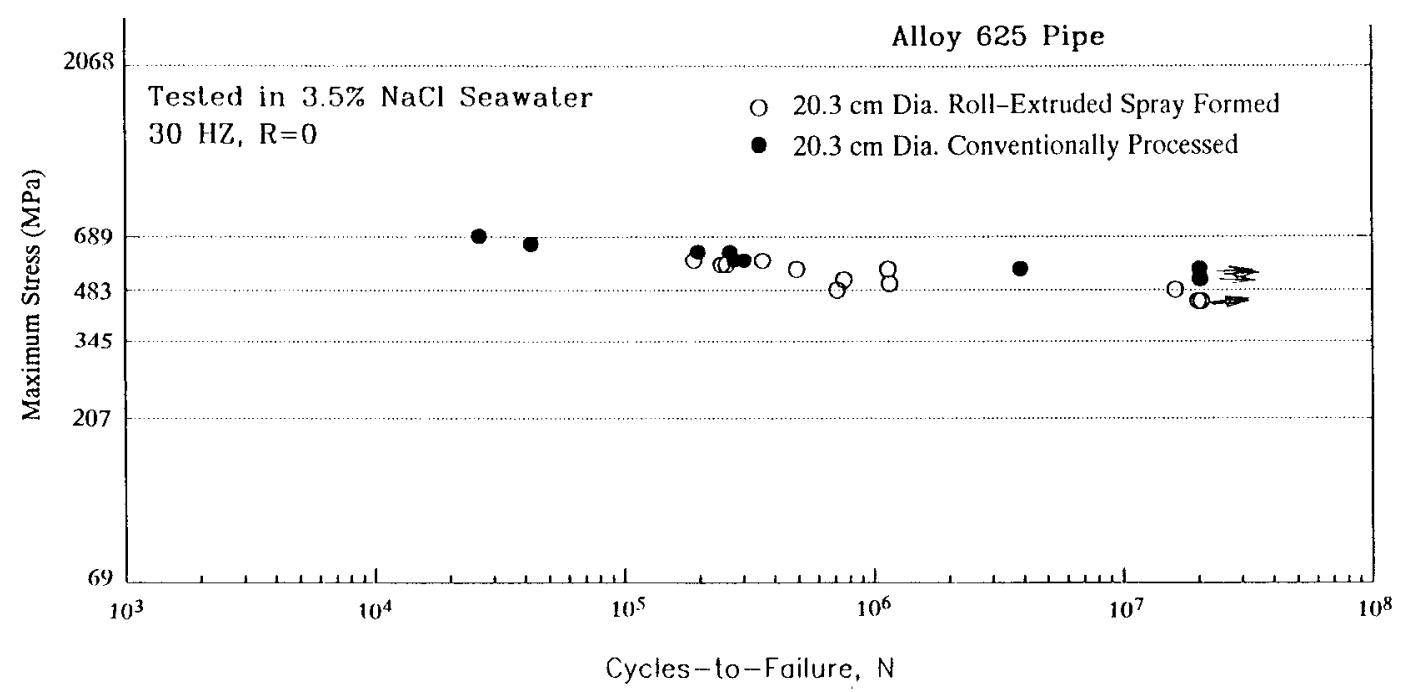

Figure 4. S-N curve for the spray formed Alloy 625 roll-extruded and conventionally processed

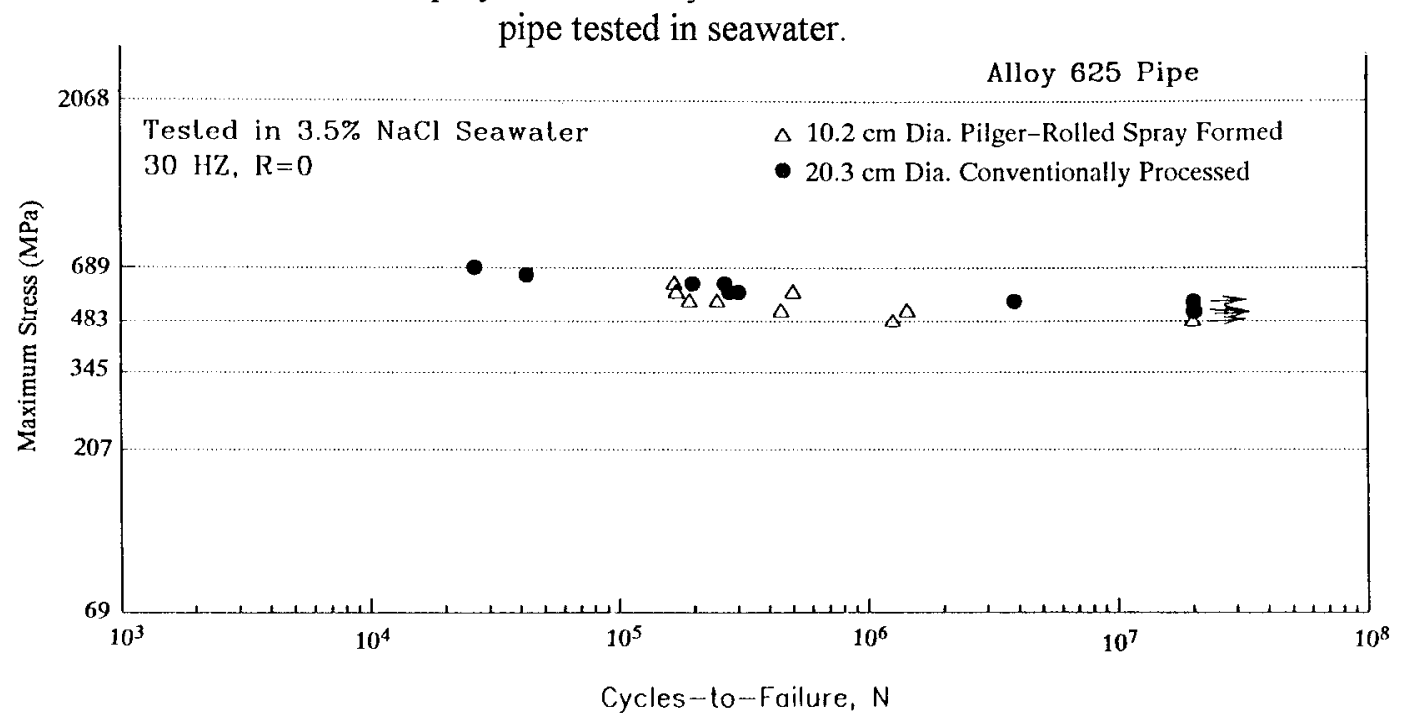

Figure 5. S-N curve for the spray formed Alloy 625 pilger-rolled and conventionally processed pipe tested in seawater.

Table III. Thermal crack susceptible regions of spray formed and conventional Alloy 625 .

\begin{tabular}{|c|c|c|}
\hline MATERIAL & $\begin{array}{c}\text { SPRAY FORMED 625 } \\
\text { PREFORMS }\end{array}$ & $\begin{array}{c}\text { CONVENTIONAL 625 } \\
\text { (LIPPOLD ET AL, 1992) }\end{array}$ \\
\hline APP. MELTING TEMP, $\mathrm{T}_{\mathbf{L}}\left({ }^{\circ} \mathrm{C}\right)$ & 1349 & 1322 \\
\hline ZERO-DUCTILITY TEMP, ZDT $\left({ }^{\circ} \mathrm{C}\right)$ & $1260-1302$ & 1220 \\
\hline ZERO-STRENGTH TEMPERATURE, ZST $\left({ }^{\circ} \mathrm{C}\right)$ & $1343-1349$ & 1313 \\
\hline $\begin{array}{c}\text { DUCTILITY RECOVERY TEMPERATURE, } \\
\text { DRT }_{\text {ZST }}\left({ }^{\circ} \mathrm{C}\right)\end{array}$ & $1154-1182$ & 146 \\
\hline $\begin{array}{c}\text { ON HEATING CRACK SUSCEPTIBLE REGION, } \\
\text { CSR }\left(\mathrm{T}_{\mathrm{L}} \text {-ZDT) }\right.\end{array}$ & $29-71$ & \\
\hline $\begin{array}{c}\text { ON COOLING BRITTLE TEMPERATURE } \\
\text { RANGE, BTR }\end{array}$ ZST $($ ZST-DRT) & $143-171$ & \\
\hline
\end{tabular}


The specification requirements and tensile results from test weldments in spray formed alloy 625 and conventional alloy 625 piping indicated that the weldment tensile strengths exceeded the specification requirement, ranging from 773 to $890 \mathrm{MPa}$. In general, the weldment tensile strengths were below the tensile strength of the pipe. Additionally, all weldment specimens fractured in the weld metal, also indicating that the weld metal tensile strength was less than that of the pipe. Table IV presents the CVN results from the simulated-HAZ specimens. Results from the as-sprayed preforms are included for comparison. The data show that the HAZ and as-sprayed materials displayed comparable CVN properties.

\section{Corrosion Testing}

Crevice corrosion testing was conducted on $20.3 \mathrm{~cm}$ diameter conventionally manufactured Alloy 625 piping, spray formed/roll extruded piping, and spray formed/pilger rolled piping. This testing was conducted for 60 days in $30^{\circ} \mathrm{C}$ filtered seawater. For the conventionally produced Alloy 625 piping, eight sites out of 156 sites (5\%) were attacked. The spray formed/roll extruded $20.3 \mathrm{~cm}$ diameter piping was immune to crevice corrosion on all of the 132 sites tested. For the spray formed/pilger rolled $20.3 \mathrm{~cm}$ diameter piping, 11 sites out of 68 sites $(16 \%)$ were attacked. Based on this data, it appears that the crevice corrosion susceptibility of the piping manufactured from spray formed preforms via roll extruding is comparable to that of the conventionally produced material. Although the spray formed/pilger rolled material showed a slightly higher incidence of attack and slightly more active corrosion potentials during testing, this data was not considered sufficient to conclude that this material was significantly more susceptible to crevice attack than the spray formed/roll extruded or conventionally produced materials.

Crevice corrosion testing of GTA and SMA welded $20.3 \mathrm{~cm}$ diameter spray form/roll extruded, spray form/pilger rolled and conventional Alloy 625 piping was also conducted for 60 days in $30^{\circ} \mathrm{C}$ filtered, seawater. The results were that 4 of the 16 welded crevice sites on the conventional piping were attacked, 1 of 16 welded crevice sites on the spray form/roll extruded piping were attacked, and 1 of 16 welded crevice sites on the spray formed/pilger rolled piping were attacked. This incidence of attack ( 6 out of 48 sites, $12.5 \%$ ) is approximately twice that observed for the base metal (19 sites out of 356, 5.3\%) indicating that crevices formed on welds in Alloy 625 should be more prone to crevice corrosion than those formed on base materials. Of the six weld metal sites which corroded, four of the sites were GTA welds and two were SMA welds. In light of the low incidence of attack, it is not believed that this result indicates that GTA welds are more susceptible to crevice corrosion than SMA welds. In most cases, preferential attack in the fusion zone/heat affected zone was observed.

The results of the base metal and weldment testing suggest that the spray formed/roll extruded piping has crevice corrosion performance that is equivalent to the conventionally produced material. The spray formed/pilger rolled material showed a slightly higher incidence of attack. However, this data was not considered sufficient to conclude that this material was significantly more susceptible to crevice attack than the spray formed/roll extruded or conventionally produced materials.

The results of stress corrosion cracking evaluation via slow strain rate testing included the breaking loads at various potentials divided by the breaking loads in air. This allows for comparisons between the three product forms and mitigates the impact of wall thickness variability between the product forms. The results indicated that no significant reduction in breaking load occurs at open circuit conditions or $-0.85 \mathrm{mV}$ vs. SCE, which is the standard target potential for Impressed Current Cathodic Protection (ICCP) systems on Navy ships. At $-1.00 \mathrm{~V}$ vs. SCE, which is the potential of zinc or aluminum sacrificial anode cathodic protection systems, the roll extruded and pilger rolling 
spray formed piping experienced an average of $11 \%$ reduction in maximum load compared to spccimens tcstcd in air. The conventionally processed piping exhibited the smallest average reduction in maximum load (5\%) at $-1.0 \mathrm{mV}$ vs. SCE. Specimens tested at very negative potentials, $-1.250 \mathrm{~V}$ vs. SCE, were significantly less resistant to hydrogen assisted cracking. All specimens tested experienced sharp reductions in maximum load as compared to the same materials tested in air. Both the pilger rolled and roll extruded piping tested at $-1.25 \mathrm{~V}$ vs. SCE experienced the greatest reduction in average maximum loads ( $29 \%$ and $33 \%$, respectively). The average maximum load of the conventionally processed piping, although less severely affected than the spray formed based material, was $16 \%$ less than the average maximum load for specimens tested in air. Significant reduction in the load bearing capability of any of the three test materials did not occur until specimens were tested at very negative potentials $(-1.250 \mathrm{~V}$ vs. SCE). This potential is significantly more negative than would be seen in service with zinc or aluminum sacrificial anode cathodic protection. Testing at lower potentials increases the hydrogen overpotential and the concentration of hydrogen available to diffuse into the test specimen. Consequently, the environment at this potential is likely to be more aggressive than the worst case scenario envisioned in shipboard service. Testing performed under freely corroding conditions most closely resembles the expected shipboard environment for the majority of a sea water piping system. Typically a sea water piping system is not cathodically protected with the exception of piping ends located in the proximity of anodes or in electrical contact with less noble materials. In service the sea water piping potential would be expected in the range of -90 to $-120 \mathrm{mV}$, the open circuit potential of Alloy 625 in sea water. Under freely corroding conditions, the performance of all three materials was comparable to corresponding specimens tested in air. No embrittlement was evident at potentials expected for sea water piping service.

\section{$\underline{\text { Conclusions }}$}

A minimal amount of cold working is required on the as-sprayed Alloy 625 preforms for them to meet the requirements of the EB $3200 \mathrm{C}$ specification. Spray formed Alloy 625 piping subjected to standard amounts of cold reduction performed comparably to the conventionally processed Alloy 625 piping and met the chemical analysis specifications and metallurgical requirements for porosity, oxide content and grain size required for Navy applications. The tensile strength and ductility of all the roll extruded and pilger rolled pipes easily exceeded the minimum requirements while results of the hardness testing and Charpy impact testing showed no significant difference between the as-sprayed preforms, the spray formed and processed thin-walled piping, and the conventionally produced piping. Results of the fatigue testing of the spray formed Alloy 625 pipes indicate that post processing is necessary to achieve the fatigue performance in terms of endurance limit of conventionally processed Alloy 625 pipes. Of the two post processing methods employed in this study, both methods diminished porosity and produced a fine grain size but roll-extrusion yielded a more uniform microstructure and the better fatigue and strength properties. The weldability evaluation indicated that the hot-cracking resistance and mechanical properties of the welded, spray formed Alloy 625 products were at least equivalent to that of conventional Alloy 625. Additionally, spray formed Alloy 625 piping performed comparably in corrosion testing to wrought piping. Thus, Alloy 625 piping produced from spray formed tubulars appears to be a viable substitute for conventionally produced Alloy 625 piping. 
Table IV. Room temp Charpy V-notch results for Alloy 625 simulated HAZ specimens.

\begin{tabular}{|c|c|c|}
\hline MATERIAL & SPECIMEN TYPE & ABSORBED ENERGY $(J)$ \\
\hline 20.3 CM PREFORM & HAZ & $\begin{array}{c}27,28,30,20,27 \\
27 \text { AVERAGE }\end{array}$ \\
\hline 20.3 CM PREFORM & HAZ & $\begin{array}{c}38,37,30,35,37 \\
35 \text { AVERAGE }\end{array}$ \\
\hline 20.3 CM PRFFORM & BASE METAI, & 23 AVERAGE \\
\hline 20.3 CM PREFORM & BASE METAL & 27 AVERAGE \\
\hline
\end{tabular}

All specimens were subsize $0.318 \times 1.00 \mathrm{~cm}$

\section{Acknowledgements}

The significant technical assistance of John DeLoach, Richard Hays, Lisa O'Connor, Harry Sussman, Joel Patton, Linda Link, Eric Focht, Robert DeNale, and William Palko is greatly appreciated. Additionally, the efforts of Robert Mattox, Steven Szpara, Rochelle Payne, Robert Meiklejohn, Alan Cohn, Harry Prince, David Meldrum and the LaQue Center for Corrosion Testing are acknowledged. This work was supported by Ms. Sharon Allen and Mr. Fred Howell of the Foreign Comparative Test Office.

\section{$\underline{\text { References }}$}

1. A.L. Moran and W.A. Palko, "Spray Forming Alloy 625 Marine Piping," Journal of Metals, Vol. 40, Dec 1988, pp 12-15.

2. A.L. Moran, M. Yaman and A. Wilson, "Large Scale Production of Spray Deposited Tubes in Alloy 625", Advances in Powder Metallurgy \& Particulate Materials, (Princeton, NJ: Metal Powder Industries Federation/American Powder Metallurgy Institute, 1992), p.337-348.

3. J.C. Lippold, T.W. Nelson, and W. Lin, "Weldability Testing of Alloy 625 and Inconel 690", Recent Developments in the Joining of Stainless Steels and High Alloys: Proceedings of the 8th Annual North American Welding Research Conference, (Columbus, OH: Edison Welding Institute, Oct 1992). 